\title{
Experimental studies and multi-response optimisation of duplex turning parameters using grey relational analysis with entropy measurement
}

\section{Sunil Kumar*}

Department of Mechanical Engineering,

Babu Banarasi Das University,

Lucknow, 226028, India

Email: sonkar.sunil@gmail.com

*Corresponding author

\section{Ravindra Nath Yadav}

Department of Mechanical Engineering,

BBD National Institute of Technology and Management,

Lucknow, 226028, India

Email: mechrny@gmail.com

\section{Raghuvir Kumar}

Department of Mechanical Engineering,

BN College of Engineering and Technology,

Lucknow, 226201, India

Email: raghuvir_me@gmail.com

\begin{abstract}
In present work, the effect of turning parameters like cutting velocity, feed rate, primary depth of cut (DOC) and secondary-DOC on responses like primary cutting force $(\mathrm{Fp})$, secondary cutting force $(\mathrm{Fs})$ and surface roughness (Ra) using duplex turning process are observed. The preliminary experiments and entropy-grey relational analysis (GRA) has been utilised to plan the experiment. Analysis of variance (ANOVA) analyses the influence of each parameter on the responses. It is observed that feed rate has more effect as compared to other parameters. The confirmation experiment at GRA optimal condition shows the improvement in all responses as $\mathrm{Fp}=15.34 \%, \mathrm{Fs}=17.20 \%$ and $\mathrm{Ra}=10.14 \%$ positively.
\end{abstract}

Keywords: analysis of variance; ANOVA; cutting force; surface roughness; grey relational analysis; GRA; Taguchi; turning; optimisation.

Reference to this paper should be made as follows: Kumar, S., Yadav, R.N. and Kumar, R. (2020) 'Experimental studies and multi-response optimisation of duplex turning parameters using grey relational analysis with entropy measurement', Int. J. Precision Technology, Vol. 9, No. 1, pp.71-90.

Biographical notes: Sunil Kumar is a Research Scholar at the Department of Mechanical Engineering, Babu Banarasi Das University, Lucknow, India. His research area includes conventional manufacturing and metal cutting processes, modelling and optimisation of metal cutting processes. 
Ravindra Nath Yadav is presently working as a Professor in the Mechanical Department, BBD National Institute of Technology and Management, Lucknow, India. He received his $\mathrm{PhD}$ in Mechanical Engineering from the Motilal Nehru National Institute of Technology, Allahabad, India. His research interest includes traditional and non-traditional shaping processes, micro and nano machining, modelling and optimisation including FEM, soft computing and design of experiment for manufacturing processes. He is a regular reviewer of many reputed journals and published more than 50 papers in refereed journals and conference proceedings.

Raghuvir Kumar is presently associated as the Director General with the BN College of Engineering and Technology, Lucknow, India. He received his PhD in Mechanical Engineering from the University of Allahabad, India. He has supervised many $\mathrm{PhD}$ and MTech thesis's and worked at various academic posts at the Department of Mechanical Engineering, Motilal Nehru National Institute of Technology, Allahabad, India. His area of research includes design and manufacturing engineering, fracture mechanics and analysis, modelling and optimisation of design and manufacturing problems. He has published a lot of papers in the various refereed journals and conference proceedings.

\section{Introduction}

In duplex turning, two parallel tools are used and both tools are moved forward and cut the commonly shared surface with same feed/revolution, with variable depth of cut (DOC) as shown in Figure 1. Therefore, it offers less machining forces, less cutting time which helps in increasing productivity, it eliminates finishing operation as one tool performed rough turning and other tool perform finish turning, it reduces tool vibration also increases tool life as it reduces the temperature at cutting zone.

Figure 1 Configurations of duplex turning

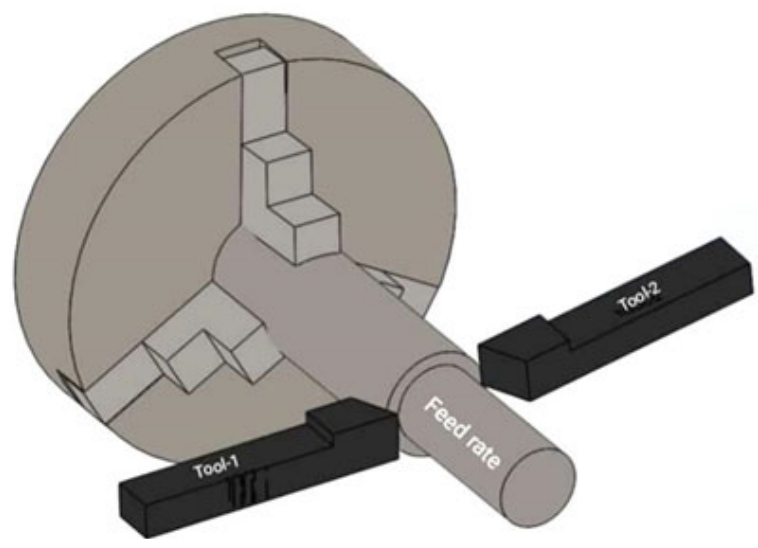

The efficiency of duplex turning process greatly depends upon machining parameters as it impacts surface quality and machining forces. The selection is either based on machine, or product to be machined but it is difficult to find best parameter combination for newly developed process (Kalidasan et al., 2014; Brecher et al., 2015; Kumar et al., 2020). 
Taguchi methodology (TM) is a very useful optimisation technique for single-response problem. However, TM shows several drawbacks when problem is highly complex and multi-objective (Mukherjee and Ray, 2006). To solve multi-objective problems in which relationship with responses are uncertain grey relational analysis (GRA) technique can be used. GRA converts multi-objective problem into single grey relational grade (GRG) (Deng, 1989; Priyadarshini and Pal, 2016; Angappan et al., 2017). The GRA optimisation has been used in various machining problems and can effectively optimise the duplex turning parameters.

\section{Literature review}

The utilisation of two-tools in turning was first discussed by Tang et al. (2008), they optimised the duplex turning parameters by utilising heuristic particle swarm technique and found that the proposed optimisation technique reduced cutting time as well as solve the machining problem very effectively. Budak and Ozturk (2011) utilised the stability model of duplex turning and compared it experimentally. They found better surface quality and chatter-free surfaces at primary-DOC $=1.5 \mathrm{~mm}$ and secondary-DOC $=$ $0.5 \mathrm{~mm}$.

Kalidasan et al. (2014) performed the experiments by varying offset distance of two parallel tools in turning. They observed that cutting forces increased significantly by increasing tool offset distance. Brecher et al. (2015) analysed the effect of radial angle of tool and cutting speed. They observed that chip removal rate increases significantly at increasing cutting speed. They also observed the improvement in cutting performance at appropriate radial angle. Kalidasan et al. (2016) performed experiments with two tools in turning. They observed the reduction in diametric error at cutting speed as $116 \mathrm{~m} / \mathrm{min}$, feed as $0.24 \mathrm{~mm} / \mathrm{rev}$ and DOC as $1.0 \mathrm{~mm}$. They also found that secondary tool experienced higher cutting temperature as compared to primary tool. Yadav (2017) used two-tools in turning and analysed surface quality at varying DOC's, speed and feed rate. They found that low feed rate and secondary-DOC produced better surface quality. Kumar et al. (2017) analysed the duplex turned parameters effect in turning of Ti-alloy. They observed the improvement in surface quality and machining forces at higher cutting velocity. Kalidasan et al. (2017) analysed the parameters effect in turning of cast iron and steel. They revealed that surface quality of both the materials increased with increasing feed rate. Yadav (2018) developed the model for cutting forces and surface roughness. They revealed that developed model was very well fitted to experimental values.

The research work related to turning effects are discussed here briefly. Bouacha et al. (2010) analysed the variation of parameters in turning of steel. They revealed that cutting speed influenced the surface quality and DOC influenced cutting forces. Chinchanikar and Choudhury (2013) analysed the parameter effects in turning of hard steel. They revealed that flank wear influenced surface quality and also dimensional accuracy. Satyanarayana et al. (2015) analysed the influence of feed rate, DOC and cutting velocity in turning of Ti-alloy. They found better surface quality at cutting velocity of $75 \mathrm{~m} / \mathrm{min}$. Manivel and Gandhinathan (2016) analysed the effects of parameters in turning. They revealed that surface quality improved at higher cutting velocity. Meddour et al. (2018) analysed the variation of nose radius, DOC, cutting speed and feed rate in turning of 
steel. They observed low feed rate and nose radius works in favour of surface quality and cutting forces. Zerti et al. (2019) analysed the variation of parameters in turning of steel. They observed that feed rate affects the surface quality while DOC affects the cutting forces.

The GRA technique was successfully tested by various researchers and some of them are discussed here briefly. The weighted-GRA method was utilised by Pawade and Joshi (2011) in turning of Ni-718 alloy. They found maximum GRG and better surface quality with moderate machining forces at low feed rate, DOC and high cutting speed. Suhail et al. (2012) utilised GRA in turning for analysing surface roughness, vibration and workpiece temperature. They observed the improvement in all responses at optimum condition of GRA. Pradhan (2012) utilised GRA in EDM at varying cutting parameters. They observed the improvement in surface quality at optimal condition of GRA. Yadav and Yadava (2015) observed the improvement in surface quality and material removal at optimum condition of GRA. Gopikrishnan et al. (2015) utilised GRA in micro-turning of Cr-cobalt alloy at different level of parameters. They observed that speed of $17.6 \mathrm{~mm} / \mathrm{min}$, feed rate of $4 \mu \mathrm{m} / \mathrm{rev}$ and DOC of $15 \mu \mathrm{m}$ were found good for surface quality. Sivaiah and Chakradhar (2017) utilised GRA in turning of steel in cryogenic condition. They observed the improvement in surface quality, material removal and wear at GRA optimal condition.

Angappan et al. (2017) utilised GRA in turning of Ni-800 alloy. They observed overall improvement in responses as $48.98 \%$ at cutting velocity $=35 \mathrm{~m} / \mathrm{min}$, feed rate $=$ $0.06 \mathrm{~mm} / \mathrm{rev}$ and DOC $=1.0 \mathrm{~mm}$. Viswanathan et al. (2018) utilised GRA in turning of Mg-alloy. They observed the improvement in surface quality at optimal condition. Thakur et al. (2019) utilised GRA in turning of steel by adding silicon particles by weight $(0.5 \%, 1 \%$ and $1.5 \%)$ with minimum quality lubricant (MQL). They observed that SiC-nano fluid gives better surface quality as compared to MQL. Suneesh and Sivapragash (2019) utilised $\mathrm{L}_{18}$ (OA) with GRA in turning of $\mathrm{Mg} / \mathrm{Al}$ composite under MQL condition. They observed that feed rate had a maximum contribution $(53.33 \%)$ on GRG, followed by DOC (16.38\%).

Generally, GRG has been calculated by aggregating all values of grey relational coefficient (GRC). But the responses show distinct behaviour concerning process factors variation, therefore grey entropy weight measurement techniques had been utilise by few researchers (Rao and Yadava, 2009; Sharma and Yadava, 2011; Kumar et al., 2019). Pradhan (2018) utilised entropy-weight with GRA in EDM process. They found the effectiveness of the approach. Velayutham et al. (2018) utilised entropy-weight with GRA in laser cutting of stainless steel thin plate. They observed that proposed optimisation technique gives better results. Palanisamy and Selvaraj (2018) utilised entropy-weight with GRA in turning of Ni-800H alloy. They found that the responses get improved by $39.07 \%$ by using GRA.

In this work, parameters of duplex turning are analysed for multi-responses using GRA optimisation. For this, firstly parameter ranges are selected by using preliminary experimental observation and then, Taguchi $\mathrm{L}_{9}(\mathrm{OA})$ is used for experimental work and entropy weighted GRA approach is used for optimising cutting speed, feed rate, primary-DOC and secondary-DOC. The primary cutting force, secondary cutting force and surface roughness are considered as multiple responses. Finally, the optimal result of GRA is experimentally confirmed and discussed. 


\section{Experimental procedure}

All experiments are performed on Lathe machine attached with secondary tool post. In this process, two tools are used both tools operate with same speed and feed rate. The process of duplex turning is given in Figure 2.

Figure 2 Photographic view of experimental setup (see online version for colours)

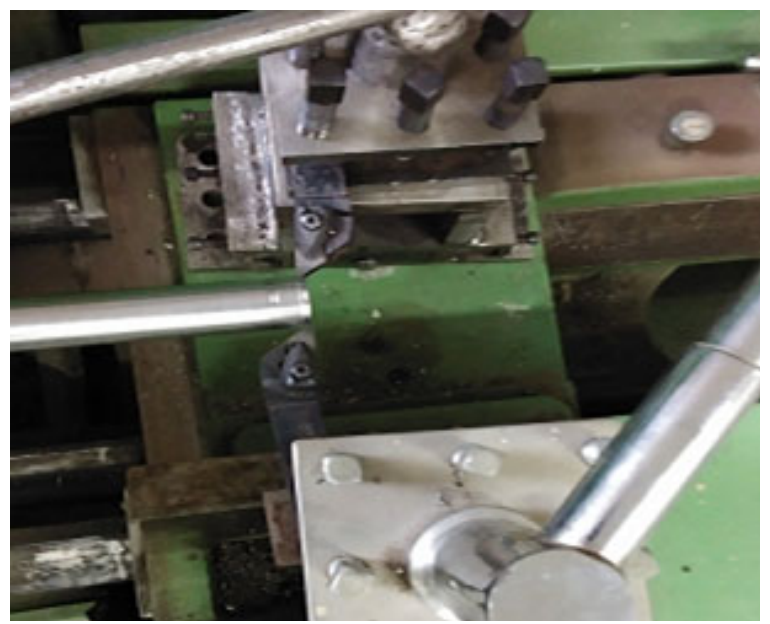

Work material for experiments is Ti-alloy (diameter $=25 \mathrm{~mm}$ and length $=300 \mathrm{~mm}$ ). The chemical composition of Ti-alloy is listed in Table 1. The carbide tool is taken for experimentation purpose. The parameters for experimentation are cutting velocity (V), feed rate (f), primary-DOC (Dp) and secondary-DOC (Ds). The multi-responses are primary force (Fp), secondary force (Fs) and average surface roughness (Ra), respectively. For measuring surface roughness, a TR-200 surface roughness tester is used and for measuring cutting forces, strain gauge dynamometer is used.

Table 1 Chemical composition of Ti-alloy (\%)

\begin{tabular}{lcccc}
\hline$T i$ & $A l$ & $M o$ & $F e$ & $V$ \\
\hline 88.67 & 6.28 & 0.14 & 0.50 & 4.41 \\
\hline
\end{tabular}

The levels of parameters are decided by preliminary observation and listed in Table 2 . Experimental data according to $\mathrm{L}_{9} \mathrm{OA}$ is listed in Table 3. Further, signal to noise (S/N) ratio and normalised $\mathrm{S} / \mathrm{N}$ ratio is obtained for analysis according to GRA technique.

Table 2 Parameters and levels for $\mathrm{L}_{9}$ experimentation

\begin{tabular}{lcccc}
\hline Cutting parameters & Symbol & Level 1 & Level 2 & Level 3 \\
\hline Cutting velocity $(\mathrm{m} / \mathrm{min})$ & $\mathrm{V}$ & 50 & 70 & 90 \\
Feed rate $(\mathrm{mm} / \mathrm{rev})$ & $\mathrm{f}$ & 0.12 & 0.16 & 0.20 \\
Primary-DOC $(\mathrm{mm})$ & $\mathrm{Dp}$ & 0.40 & 0.60 & 0.80 \\
Secondary-DOC $(\mathrm{mm})$ & $\mathrm{Ds}$ & 0.20 & 0.30 & 0.40 \\
\hline
\end{tabular}


Table 3 Experimental data using $\mathrm{L}_{9}(\mathrm{OA})$

\begin{tabular}{|c|c|c|c|c|c|c|c|}
\hline \multirow{2}{*}{$\begin{array}{l}\text { Exp. } \\
\text { no. }\end{array}$} & \multicolumn{4}{|c|}{ Parameter levels } & \multicolumn{3}{|c|}{ Responses } \\
\hline & $V$ & $f$ & $D p$ & $D s$ & $F p$ & Fs & $R a$ \\
\hline 1 & 1 & 1 & 1 & 1 & 78.46 & 76.23 & 2.07 \\
\hline 2 & 1 & 2 & 2 & 2 & 87.21 & 81.23 & 2.11 \\
\hline 3 & 1 & 3 & 3 & 3 & 107.91 & 98.10 & 2.13 \\
\hline 4 & 2 & 1 & 2 & 3 & 77.21 & 82.23 & 2.01 \\
\hline 5 & 2 & 2 & 3 & 1 & 91.23 & 79.23 & 2.69 \\
\hline 6 & 2 & 3 & 1 & 2 & 99.10 & 90.23 & 2.98 \\
\hline 7 & 3 & 1 & 3 & 2 & 87.21 & 76.23 & 1.98 \\
\hline 8 & 3 & 2 & 1 & 3 & 76.21 & 86.21 & 2.03 \\
\hline 9 & 3 & 3 & 2 & 1 & 101.21 & 76.21 & 3.02 \\
\hline
\end{tabular}

\section{Preliminary experimental observations}

\subsection{Range of cutting speed}

The variation of cutting velocity $(30-110 \mathrm{~m} / \mathrm{min})$ at $\mathrm{f}=0.08 \mathrm{~mm} / \mathrm{rev}, \mathrm{Dp}=0.2 \mathrm{~mm}$ and $\mathrm{Ds}=0.2 \mathrm{~mm}$ on responses $\mathrm{Ra}, \mathrm{Fp}$ and Fs are presented in Figures 3(a)-3(c). It is observed from Figure 3(a) that Ra values of the turned surface decrease with increasing the cutting velocity from 30 to $90 \mathrm{~m} / \mathrm{min}$ and after that $\mathrm{Ra}$ increase from 90 to $110 \mathrm{~m} / \mathrm{min}$. The reason might be that, due to high thermal influence at cutting region the discontinuities get smeared out and surface quality gets enhanced. On further increasing the velocity ( 90 to $110 \mathrm{~m} / \mathrm{min}$ ) more heat is generated which causes the blunting of tool, therefore, surface quality deteriorates.

Figure 3(b) shows that Fp decreases with increasing cutting velocity from 30 to $90 \mathrm{~m} / \mathrm{min}$ and after that $\mathrm{Fp}$ increases. Using two tools diminishes the shear stress of cutting material, therefore the magnitude of Fp decreases (30 to $90 \mathrm{~m} / \mathrm{min}$ ). For cutting velocity of $110 \mathrm{~m} / \mathrm{min}$, high amount of heat is generated and tool gets blunt, therefore, Fp increases. The similar types of observations are found in Figure 3(c) at varying cutting velocity.

From Figures 3(a)-3(c), the cutting velocity from $50 \mathrm{~m} / \mathrm{min}$ to $90 \mathrm{~m} / \mathrm{min}$ is found better for surface quality as well as for moderate cutting forces.

\subsection{Range of feed rate}

Figures 4(a)-4(c) show variation of feed rate $(0.08-0.24 \mathrm{~mm} / \mathrm{rev})$ at $\mathrm{V}=50 \mathrm{~m} / \mathrm{min}$, $\mathrm{Dp}=0.2 \mathrm{~mm}$ and $\mathrm{Ds}=0.2 \mathrm{~mm}$ on responses Ra, Fp and Fs. Figure 4(a) shows Ra of turned surface decreases from 0.08 to $0.12 \mathrm{~mm} / \mathrm{rev}$ and after that Ra increases with increasing the feed rate. High feed rate significantly increase the frictional resistance. This causes the increase in tool tip temperature and results in poor surface quality. The effect is more predominant from 0.2 to $0.24 \mathrm{~mm} / \mathrm{rev}$. 
Figure 3 Cutting velocity vs. (a) Ra, (b) Fp and (c) Fs

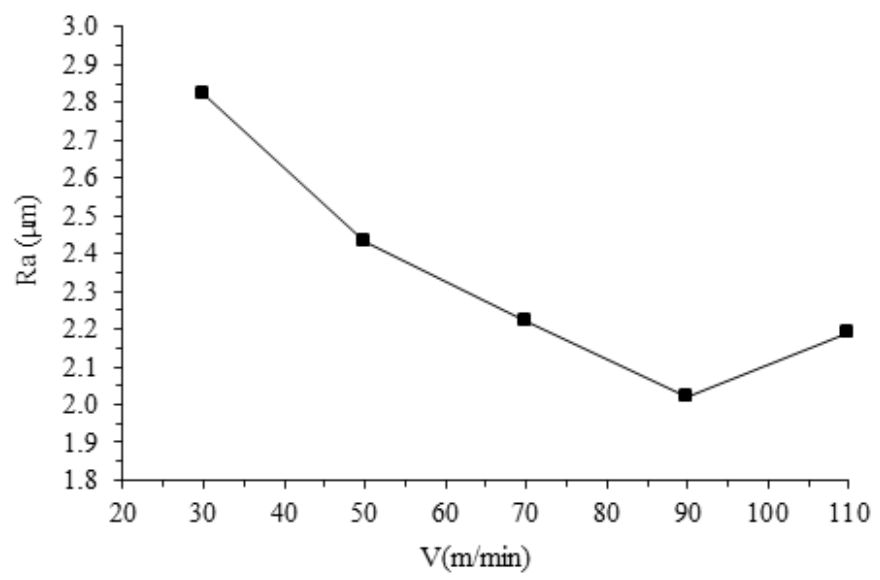

(a)

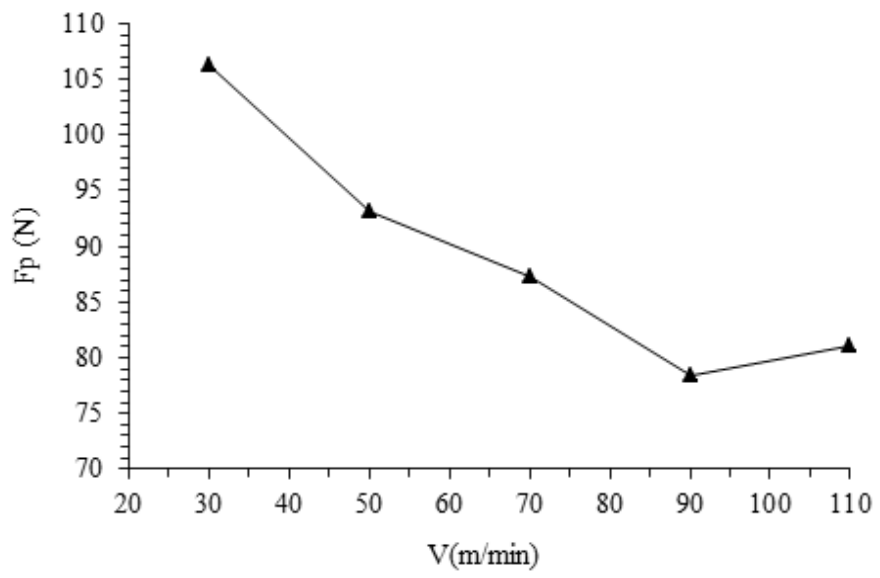

(b)

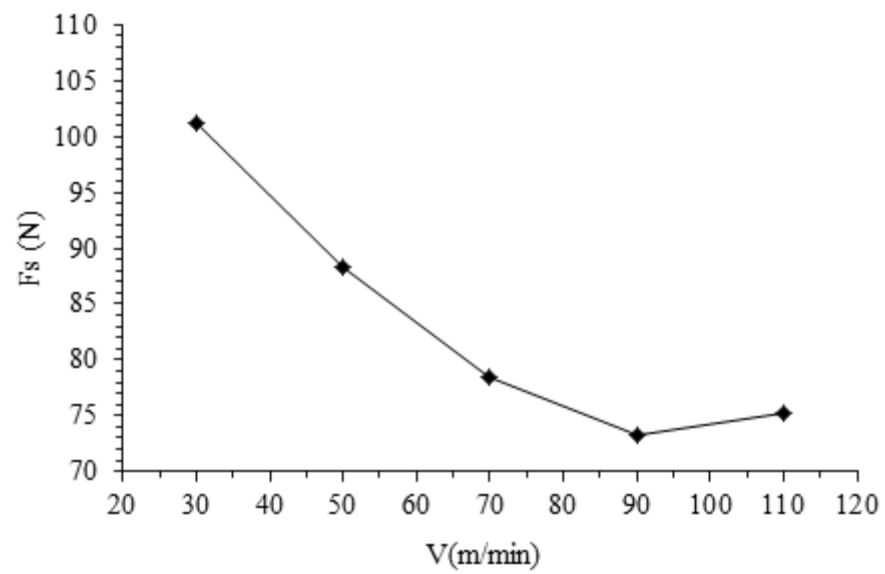

(c) 
Figure 4 Feed rate vs. (a) Ra, (b) Fp and (c) Fs

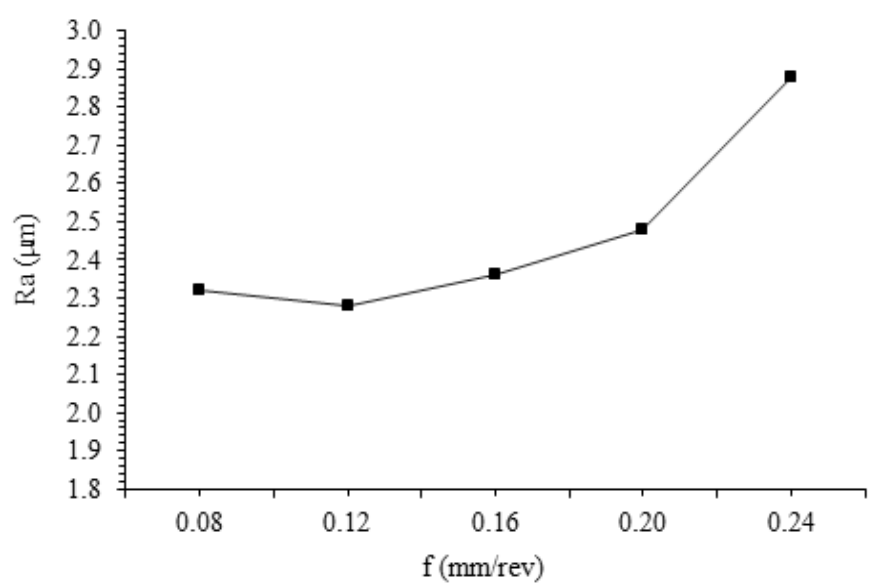

(a)

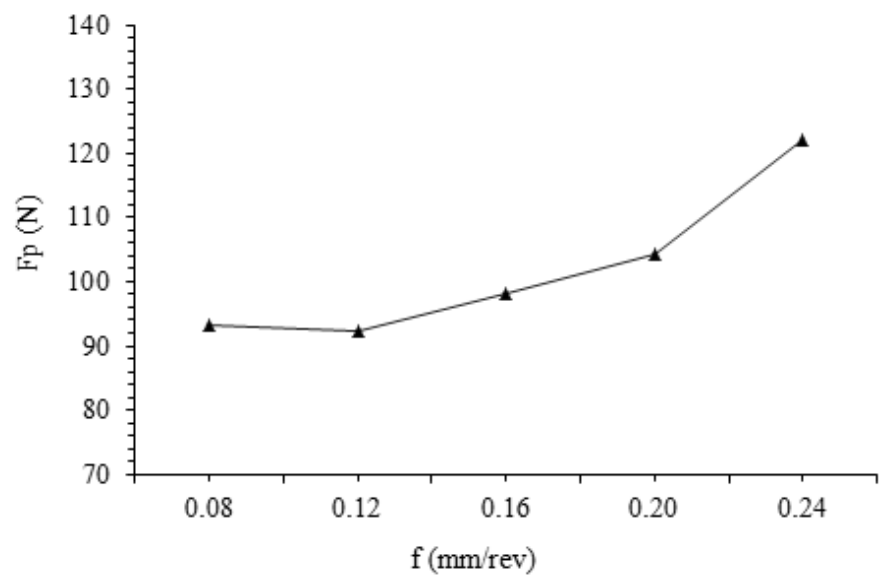

(b)

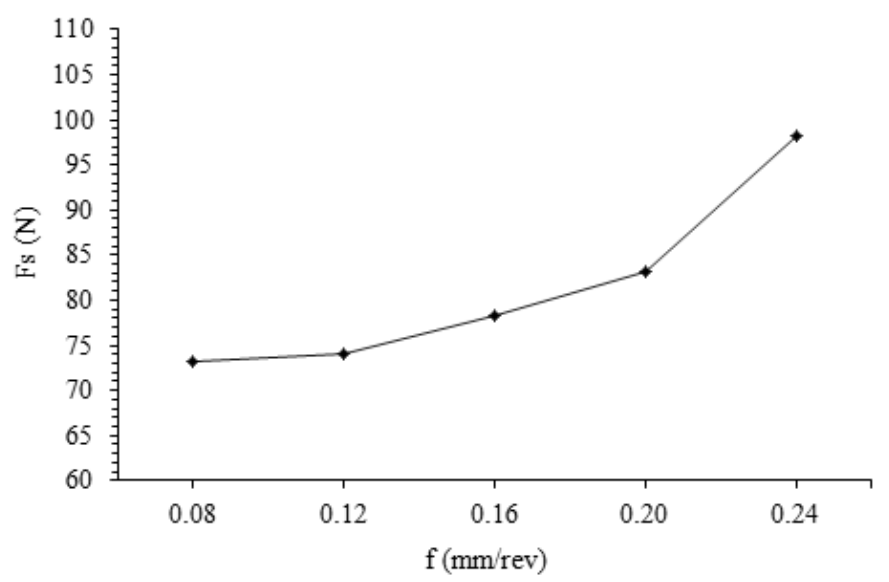

(c) 
Figure 5 Primary-DOC vs. (a) Ra, (b) Fp and (c) Fs

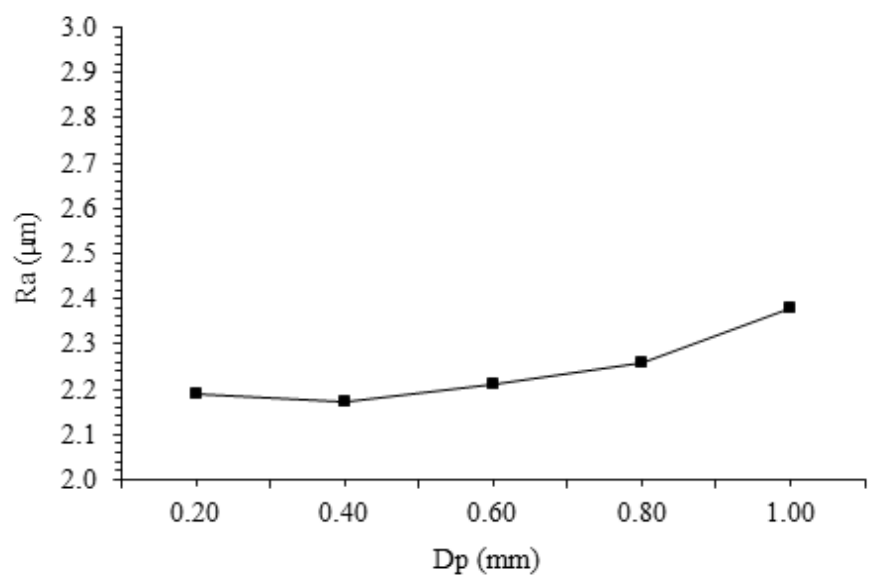

(a)

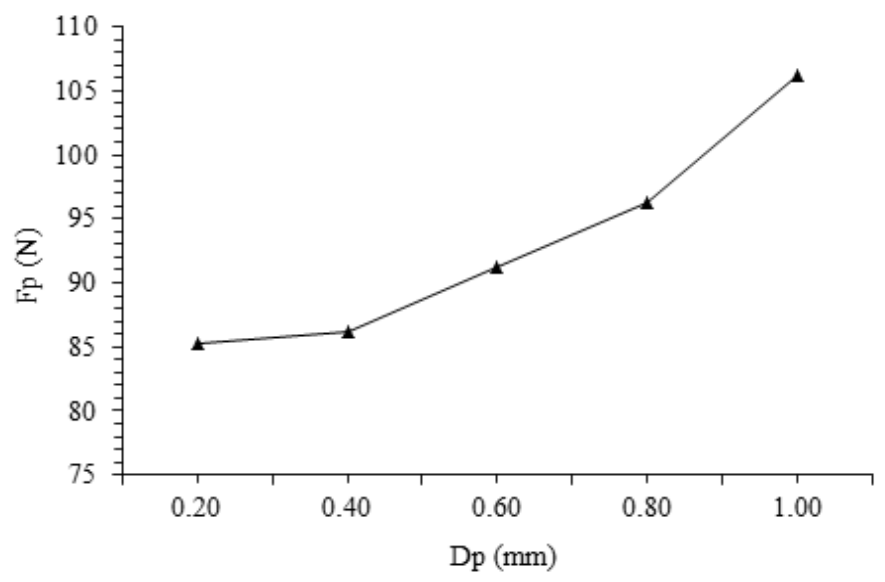

(b)

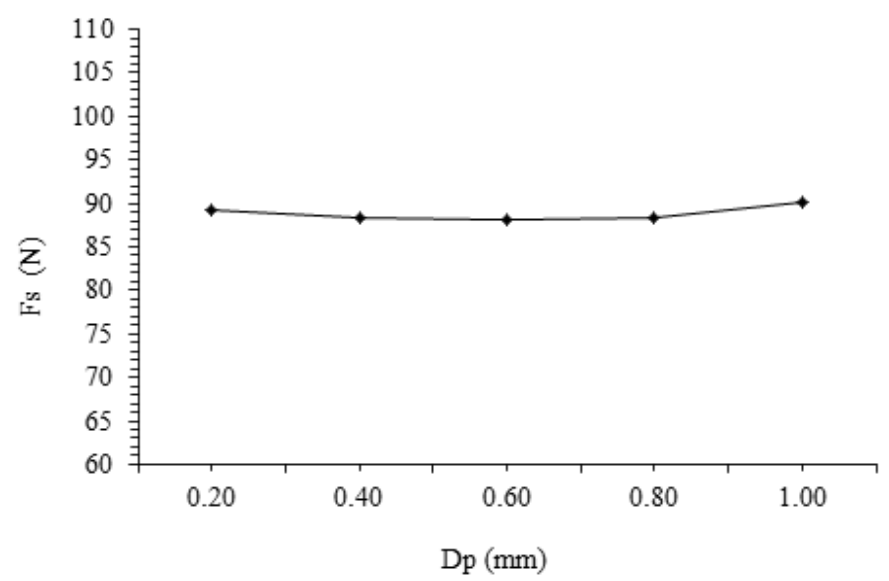

(c) 
Figure 6 Secondary-DOC vs. (a) Ra, (b) Fp and (c) Fs

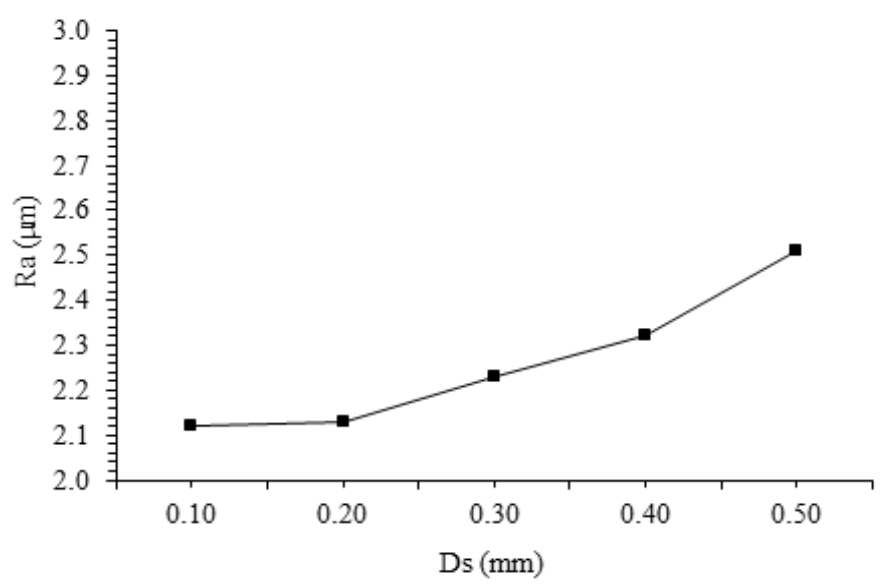

(a)

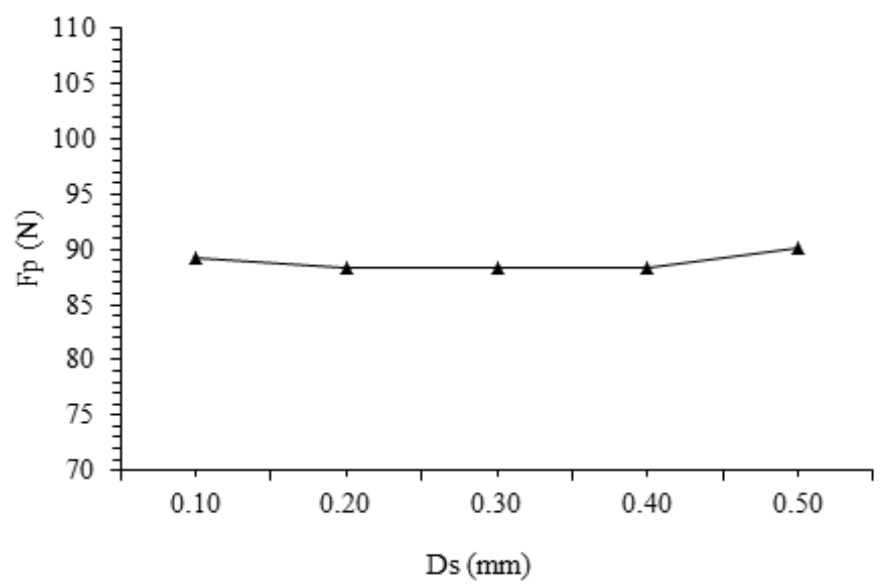

(b)

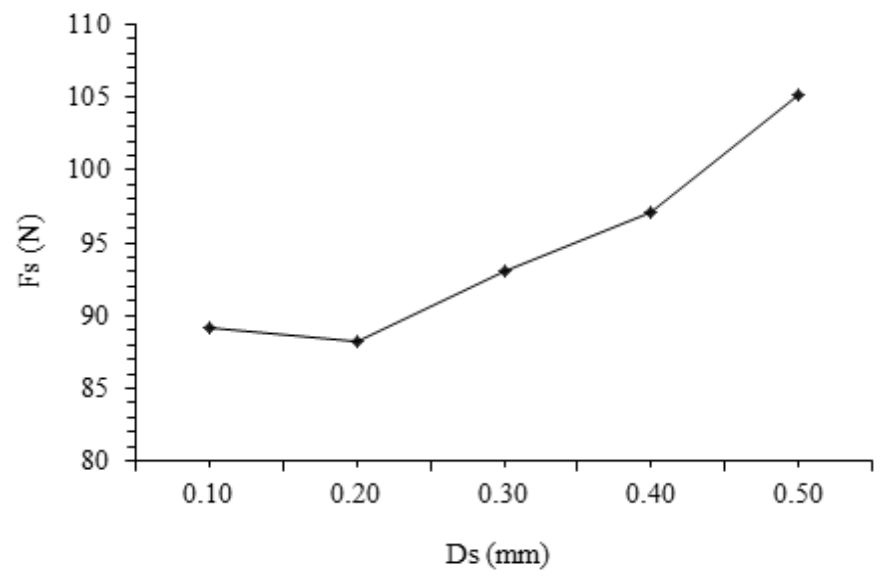

(c) 
It is observed from Figure 4(b) that Fp first decreases from 0.08 to $0.12 \mathrm{~mm} / \mathrm{rev}$ and after that Fp increases, increasing the feed rate increases the temperature at tool tip and work surface causing higher cutting forces. Figure 4(c) also shows a similar type of behaviour.

From Figures 4(a) $-4(\mathrm{c})$, the range $0.12 \mathrm{~mm} / \mathrm{rev}$ to $0.2 \mathrm{~mm} / \mathrm{rev}$ has been found better for surface quality as well as moderate cutting forces.

\subsection{Range of primary-DOC}

Figures 5(a)-5(c) show variation of primary-DOC $(0.2-1.0 \mathrm{~mm})$ at $\mathrm{V}=50 \mathrm{~m} / \mathrm{min}$, $\mathrm{f}=0.08 \mathrm{~mm} / \mathrm{rev}$ and $\mathrm{Ds}=0.20 \mathrm{~mm}$ on responses Ra, Fp and Fs. Figure 5(a) shows Ra decreases from 0.2 to $0.4 \mathrm{~mm}$ and after that surface quality diminishes. As DOC increase contact area of tool tip and work surface increase causes poor surface quality. This effect is more predominant at $1.0 \mathrm{~mm}$.

Figure 5(b) shows that cutting forces increases with increasing primary-DOC from 0.2 to $1.0 \mathrm{~mm}$. This may be due to an increase in undeformed chip thickness which leads to high resistance at contact area causing higher cutting forces and this phenomenon is more predominant from $0.8 \mathrm{~mm}$ to $1.0 \mathrm{~mm}$. Figure 5(c) shows secondary force remains unaffected by variation of primary-DOC.

Figures 5(a)-5(c) show primary-DOC of $0.4 \mathrm{~mm}$ to $0.8 \mathrm{~mm}$ has been better for surface quality as well as moderate cutting forces.

\subsection{Range of secondary-DOC}

Figures $6(\mathrm{a})-6(\mathrm{c})$ show variation of secondary-DOC $(0.10-0.50 \mathrm{~mm})$ at $\mathrm{V}=50 \mathrm{~m} / \mathrm{min}$, $\mathrm{f}=0.08 \mathrm{~mm} / \mathrm{rev}, \mathrm{Dp}=0.2 \mathrm{~mm}$ on responses (Ra, Fp and Fs). Figure 6(a) shows that Ra of turned surface is increasing from 0.1 to $0.5 \mathrm{~mm}$. As contact area of tool increases, surface quality diminishes and at higher DOC $(0.5 \mathrm{~mm})$ the tool may get blunt which causes poor surface quality.

Figure 6(b) shows that the Fp is not changing much by varying secondary-DOC. From Figure 6(c), it is seen that Fs decrease from 0.1 to $0.2 \mathrm{~mm}$ and after that it increases. It is observed that increasing secondary-DOC, the contact area between tool and workpiece increases, therefore, Fs increases. This effect is more predominant from 0.4 to $0.5 \mathrm{~mm}$.

Figures 6(a)-6(c) the secondary-DOC as $0.2 \mathrm{~mm}$ to $0.4 \mathrm{~mm}$ has been better for surface quality as well as for moderate cutting forces.

\section{$5 \quad$ Result and discussion}

In this section, entropy-GRA optimisation is used for finding the optimal parameter for duplex turning. For this, firstly the $\mathrm{L}_{9} \mathrm{OA}$ is performed according to Table 2 . $\mathrm{S} / \mathrm{N}$ ratio $(\eta)$ calculated from $\mathrm{L}_{9} \mathrm{OA}$ data (Table 2). This data is further used for finding the GRG and optimal setting of duplex turning using GRA optimisation. 


\subsection{TM for finding $S / N$ ratio}

In this section, $\mathrm{TM}$ experimental data $\mathrm{L}_{9}(\mathrm{OA})$ is used for calculating $\mathrm{S} / \mathrm{N}$ ratio. This $\mathrm{L}_{9}$ (OA) relies on degree of freedom (DF) and for four parameters and three levels, DF is 9 , therefore, minimum nine numbers of experiments are required for optimising experimental data (Rose, 1996; Subburam et al., 2018). The $\eta$ is calculated by equation (1) and listed in Table 4.

$$
\eta=-10 \log \frac{1}{n} \sum_{i=1}^{n} y_{i}^{2}
$$

Here, $y_{i}=$ experimental data and $n=$ number of replicates.

Table $4 \quad \mathrm{~S} / \mathrm{N}$ ratio and normalised $\mathrm{S} / \mathrm{N}$ ratio

\begin{tabular}{|c|c|c|c|c|c|c|}
\hline \multirow{2}{*}{$\begin{array}{l}\text { Exp. } \\
\text { no. }\end{array}$} & \multicolumn{3}{|c|}{$S / N$ ratio } & \multicolumn{3}{|c|}{$S / N$ ratio (normalised) } \\
\hline & $F p$ & Fs & $R a$ & $F p$ & Fs & $R a$ \\
\hline 1 & -37.8930 & -37.6425 & -6.31941 & 0.083 & 0.001 & 0.106 \\
\hline 2 & -38.8113 & -38.1943 & -6.48565 & 0.38 & 0.25 & 0.151 \\
\hline 3 & -40.6612 & -39.8334 & -6.56759 & 1.00 & 1.00 & 0.173 \\
\hline 4 & -37.7535 & -38.3006 & -6.06392 & 0.03 & 0.30 & 0.036 \\
\hline 5 & -39.2028 & -37.9778 & -8.59505 & 0.51 & 0.15 & 0.726 \\
\hline 6 & -39.9215 & -39.1070 & -9.48433 & 0.75 & 0.67 & 0.968 \\
\hline 7 & -38.8113 & -37.6425 & -5.93330 & 0.38 & 0.001 & 0.000 \\
\hline 8 & -37.6402 & -38.7112 & -6.14992 & 0.00 & 0.49 & 0.0591 \\
\hline 9 & -40.1045 & -37.6402 & -9.60014 & 0.81 & 0.00 & 1.00 \\
\hline
\end{tabular}

\subsection{Methodology of GRA}

GRA solve multi-objective optimisation problems having uncertain models and complex inter-relation. GRA utilises experimental data of TM (S/N ratio) and normalised $\mathrm{S} / \mathrm{N}$ ratio is calculated. From normalised values, GRC and GRG is calculated. Maximum GRG from all GRG values represents the desired value of the multi-response (Dieguez et al., 2007; Mohapatra et al., 2017; Babu et al., 2016). The procedures for solving GRA are as follows.

The $\mathrm{S} / \mathrm{N}$ ratio (Table 4) is normalised from zero to one by 'smaller-the-better' approach using equation (2). The normalised $\mathrm{S} / \mathrm{N}$ ratio is also listed in Table 4.

$$
z_{i}^{*}(p)=\frac{\max x_{i}(p)-x_{i}(p)}{\max x_{i}(p)-\min x_{i}(p)}
$$

Here, $i=$ number of experiments, $p=$ number of responses, $z_{i}^{*}(p)=$ normalised value, $\max x_{i}(p)=$ maximum response value, $\min x_{i}(p)=$ minimum response value and $x_{i}(p)=$ referral value.

GRC is calculated by using normalised value (Table 4) in equation (3), GRC value is listed in Table 5. It states relationship in referral and comparable sequence for each response. 


$$
\xi_{i}(p)=\frac{\Delta_{\min }+\lambda \Delta_{\max }}{\Delta_{o i}(p)+\lambda \Delta_{\max }}
$$

Here, $\xi_{i}(p)=$ GRC value of $p^{\text {th }}$ response and $\Delta_{o i}(p)=$ deviation coefficient calculated by given relations.

$$
\begin{aligned}
& \Delta_{o i}(k)=\left|x_{0}(k)-x_{i}(k)\right|, \Delta_{\max }=\max _{i} \max _{k}\left|x_{o}^{k}(k)-x_{i}^{k}(k)\right|, \\
& \Delta_{\min }=\min _{i} \min _{k}\left|x_{o}^{k}(k)-x_{i}^{k}(k)\right|
\end{aligned}
$$

Here, $\lambda=$ coefficient of distinguishing and taken as 0.50 (Tosun, 2006; Mohapatra et al., 2017; Mishra et al., 2018).

Table 5 GRC, weighted GRG and rank

\begin{tabular}{lccccc}
\hline Exp. no. & $G R C(F p)$ & $G R C(F s)$ & $G R C(R a)$ & $G R G$ & Rank \\
\hline 1 & 0.858 & 0.998 & 0.825 & 0.893 & 1 \\
2 & 0.568 & 0.667 & 0.768 & 0.667 & 5 \\
3 & 0.333 & 0.333 & 0.742 & 0.469 & 8 \\
4 & 0.943 & 0.625 & 0.932 & 0.833 & 3 \\
5 & 0.495 & 0.769 & 0.408 & 0.557 & 7 \\
6 & 0.400 & 0.427 & 0.341 & 0.389 & 9 \\
7 & 0.568 & 0.998 & 1.000 & 0.855 & 2 \\
8 & 1.000 & 0.505 & 0.894 & 0.799 & 4 \\
9 & 0.382 & 1.000 & 0.333 & 0.571 & 6 \\
\hline
\end{tabular}

GRC values (Table 5) is transformed in GRG by multiplying the weights of each response using entropy weight method. For calculating entropy weight, a function of entropy is defined in the range 0 to $(1-x)$ (Wen et al., 1998; Velayutham et al., 2018) as given by equation (4).

$$
W(A)=\frac{1}{\left(e^{0.50}-1\right) n} \sum_{i=1}^{n} W_{e}\left(X_{i}\right)
$$

$W_{e}\left(X_{i}\right)$ is used as mappings function and solved by equation (5)

$$
W_{e}\left(X_{i}\right)=x e^{(1-x)}+(1-x) e^{x}-1
$$

The weights for each GRC for responses is calculated by equations (4)-(5) and found as $\mathrm{Fp}=0.3333, \mathrm{Fs}=0.3333$ and $\mathrm{Ra}=0.3334$ positively.

After getting the GRC and weights of each GRC (Fp, Fs and Ra), the GRG is calculated by equation (6). The maximum GRG shows the closeness with desired value of the responses. The GRG are listed in Table 5.

$$
\gamma_{i}=\sum_{p=1}^{j} w_{j} \xi_{i}(p), \quad i=1, \mathrm{~K}, n .
$$

Here, $\gamma=$ GRG value and $w_{j}=$ weights assigned to each GRC. 
The GRG values (Table 5) are plotted with rank in Figure 7 and observe that rank 1 is associated with experiment number 1 from nine experimental data.

Figure 7 GRG with rank

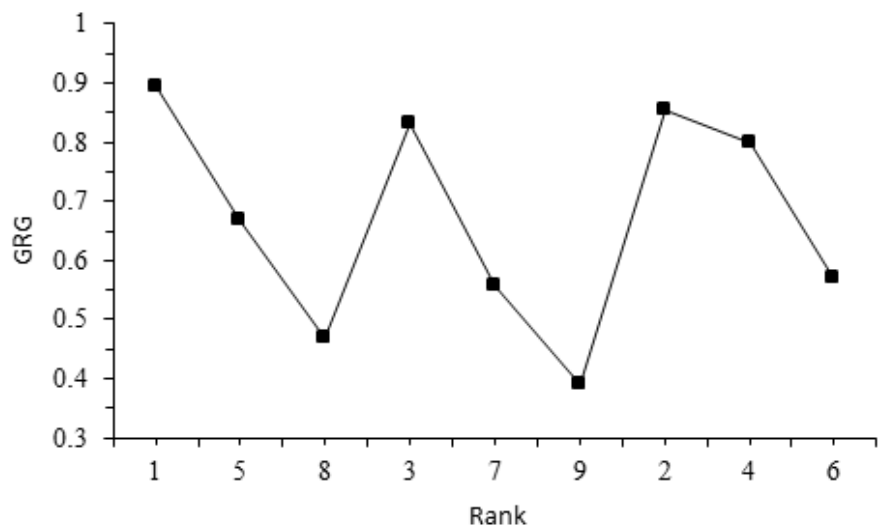

Table 6 Mean value of weighted GRG

\begin{tabular}{lccccc}
\hline \multirow{2}{*}{ Factors } & \multicolumn{5}{c}{ GRG with levels } \\
\cline { 2 - 6 } & 1 & 2 & 3 & Max. - min. & Rank \\
\hline $\mathrm{V}(\mathrm{m} / \mathrm{min})$ & 0.676 & 0.593 & 0.742 & 0.149 & 2 \\
$\mathrm{f}(\mathrm{mm} / \mathrm{rev})$ & 0.861 & 0.674 & 0.476 & 0.385 & 1 \\
Dp $(\mathrm{mm})$ & 0.694 & 0.690 & 0.627 & 0.067 & 3 \\
Ds $(\mathrm{mm})$ & 0.674 & 0.637 & 0.700 & 0.063 & 4 \\
\hline
\end{tabular}

Figure 8 Parameter level vs. GRG (see online version for colours)

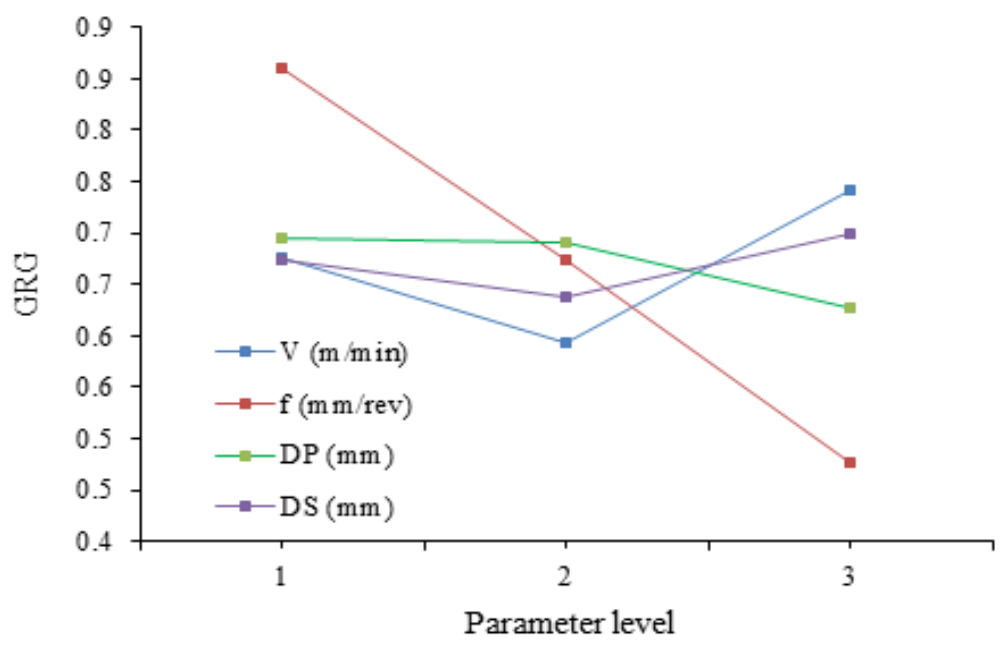


The mean GRG is listed in Table 6, plotted in Figure 8. The maximum GRG (Table 6) has given as $\mathrm{V}=90 \mathrm{~m} / \mathrm{min}, \mathrm{f}=0.12 \mathrm{~mm} / \mathrm{rev}, \mathrm{Dp}=0.40 \mathrm{~mm}$ and $\mathrm{Ds}=0.40 \mathrm{~mm}$ and it shows the optimal value and it gives moderate cutting forces (Fp and Fs) and minimum surface roughness (Ra).

Difference in GRG (Table 6) is as follows: $\mathrm{V}=0.149, \mathrm{f}=0.385, \mathrm{Dp}=0.067$ and $\mathrm{Ds}=0.063$. The maximum difference is 0.385 . It shows feed rate has a main effect on responses (Fp, Fs and $\mathrm{Ra}$ ) compared to other parameters.

\subsection{ANOVA analysis}

Analysis of variance (ANOVA) results are listed in Table 7 and it shows that percentage contributions of each cutting parameter in increasing order are Ds $=2.24 \%, \mathrm{Dp}=2.98 \%$, $\mathrm{V}=12.31 \%$, and $\mathrm{f}=82.46 \%$. The contribution of each parameter is plotted in Figure 9. From Table 7 and Figure 9, it is observed that feed rate has a maximum contribution on responses (Fp, Fs and $\mathrm{Ra}$ ) fallowed by cutting velocity, primary-DOC and secondary-DOC positively.

Table 7 ANOVA analysis

\begin{tabular}{lccccc}
\hline Factor & Sum square & DF & Mean square & F-ratio & $\%$ PC \\
\hline V & 0.033 & 2 & 0.017 & 4.250 & 12.31 \\
F & 0.221 & 2 & 0.111 & 27.75 & 82.46 \\
Dp & 0.008 & 2 & 0.004 & 1.000 & 2.98 \\
Ds & $0.006^{\#}$ & 2 & 0.003 & 0.750 & 2.24 \\
Pooled error & 0.014 & 4 & 0.004 & -- & -- \\
Total & 0.268 & 12 & -- & -- & -- \\
\hline
\end{tabular}

Figure $9 \%$ PC of parameters on responses (see online version for colours)

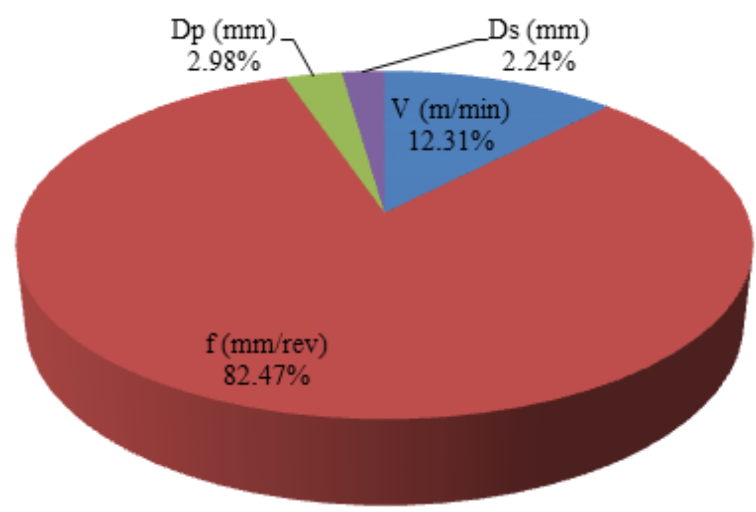

\subsection{Validation of optimal result}

The optimal result of GRA is experimentally validated to check and confirm optimal condition. The validation experiment is performed at optimum level of GRA as $90 \mathrm{~m} / \mathrm{min}$ of cutting velocity, $0.12 \mathrm{~mm} / \mathrm{rev}$ of feed rate as, $0.40 \mathrm{~mm}$ of primary-DOC and $0.40 \mathrm{~mm}$ 
of secondary-DOC. The results from confirmation test is compared with initial setting and listed in Table 8 and following improvement in responses are obtained $\mathrm{Fp}=15.34 \%$, Fs $=17.20 \%$ and $\mathrm{Ra}=10.14 \%$ positively.

Figure 10 SEM images at, (b) initial setting (b) optimal settings

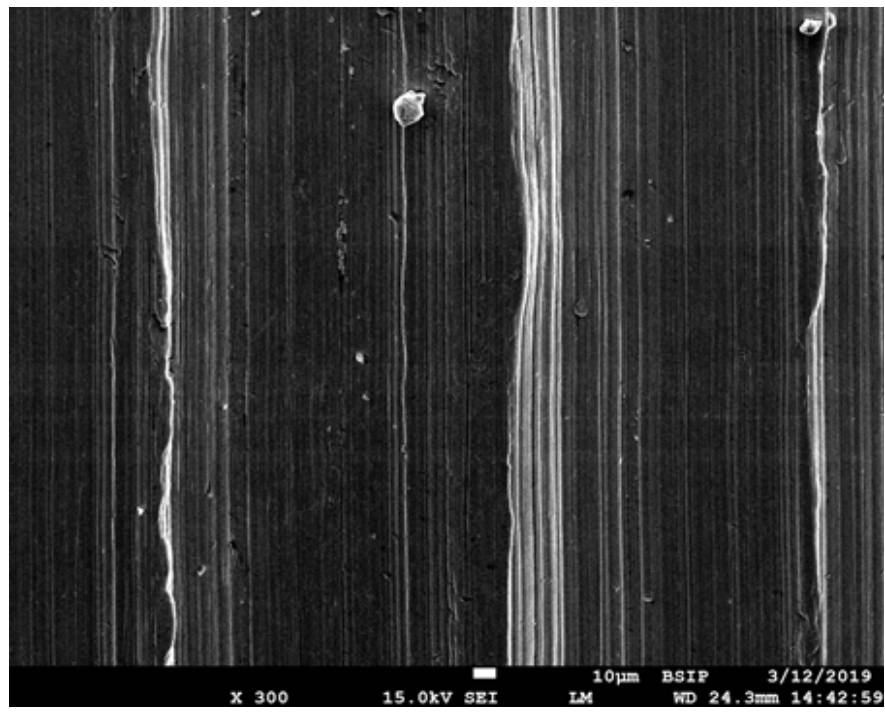

(a)

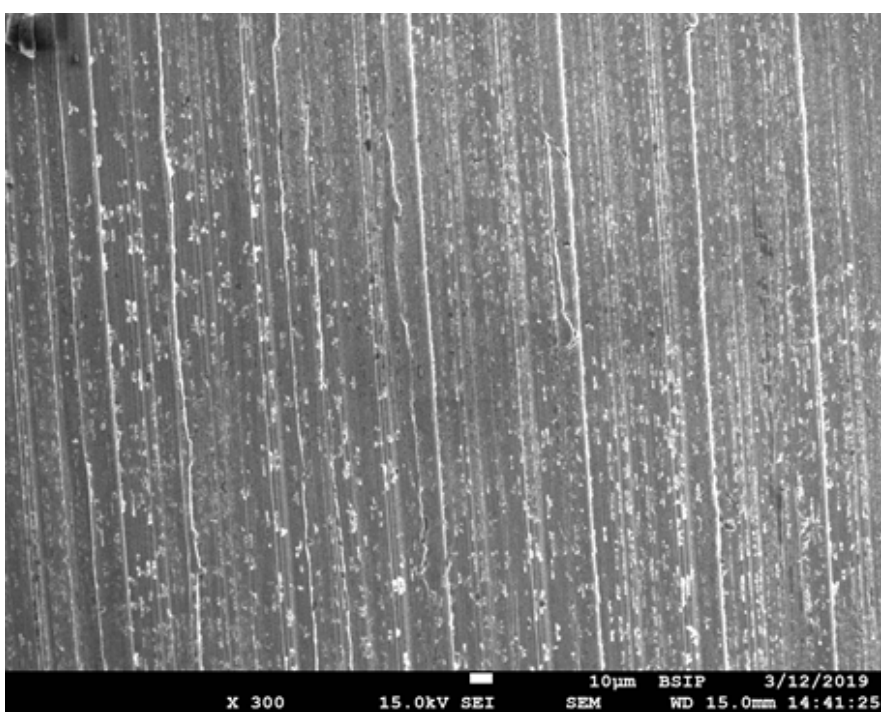

(b)

\subsection{Scanning electron microscopy analysis}

Figure 10(a) shows the scanning electron microscopy (SEM) image at initial setting $(\mathrm{V}=50 \mathrm{~m} / \mathrm{min}, \mathrm{f}=0.12 \mathrm{~mm} / \mathrm{rev}, \mathrm{Dp}=0.40 \mathrm{~mm}$ and $\mathrm{Ds}=0.20 \mathrm{~mm})$, it is seen that at low 
cutting velocity frictional resistance is high therefore high heat is generated which causes the tool marks and grooves at turned surfaces. It is also observed from high response values $(\mathrm{Fp}=78.46 \mathrm{~N}$, Fs $=76.23 \mathrm{~N}$ and $\mathrm{Ra}=2.07 \mu \mathrm{m})$. Figure $10(\mathrm{~b})$ shows the SEM image as optimal settings $(\mathrm{V}=90 \mathrm{~m} / \mathrm{min}, \mathrm{f}=0.12 \mathrm{~mm} / \mathrm{rev}, \mathrm{Dp}=0.40 \mathrm{~mm}$ and Ds $=0.40 \mathrm{~mm}$ ) which is considerable smoother as less particle deposition are observed. It is possible because at high velocity $(90 \mathrm{~m} / \mathrm{min})$, the work surface become softer and cutting tool removes the hills and valley of the work surface and better surface quality $(\mathrm{Ra}=1.86 \mu \mathrm{m})$ and moderate cutting forces $(66.42 \mathrm{~N}$ and $63.12 \mathrm{~N})$ are observed.

Table 8 Confirmation experiment

\begin{tabular}{|c|c|c|c|}
\hline \multirow{3}{*}{ Response } & \multirow{3}{*}{$\begin{array}{l}\text { Initial setting } \\
V_{I} f_{I} D P_{I} D S_{I}\end{array}$} & \multicolumn{2}{|c|}{ Optimum results } \\
\hline & & \multirow{2}{*}{$\begin{array}{c}\text { Experiment } \\
V_{3} f_{1} D P_{1} D S_{3}\end{array}$} & \multirow{2}{*}{$\%$ improvement } \\
\hline & & & \\
\hline $\mathrm{Fp}(\mathrm{N})$ & 78.46 & 66.42 & $15.34 \%$ \\
\hline Fs $(\mathrm{N})$ & 76.23 & 63.12 & $17.20 \%$ \\
\hline $\mathrm{Ra}(\mu \mathrm{m})$ & 2.07 & 1.86 & $10.14 \%$ \\
\hline
\end{tabular}

\section{Conclusions}

In this work, duplex turning experiments are carried for Ti-alloy to find the cutting range for parameters and further GRA technique has been used to optimise the control factors. For this, entropy function is used to calculate the weight of responses (Fp, Fs and $\mathrm{Ra}$ ). The results show that the maximum contribution of feed rate $=82.46 \%$ while other parameters show the contribution as $12.31 \%, 2.98 \%$ and $2.24 \%$ for cutting velocity, primary-DOC and secondary-DOC, respectively. It is also observed that combination of higher level of cutting velocity $(90 \mathrm{~m} / \mathrm{min})$, lower feed rate $(0.12 \mathrm{~mm} / \mathrm{rev})$ and primary-DOC $(0.40 \mathrm{~mm})$ with higher secondary-DOC $(0.40 \mathrm{~mm})$ is better for duplex turning of Ti-alloy within the range of selected parameters. The optimal results shows that percentage improvement in $\mathrm{Ra}=15.34 \%, \mathrm{Fp}=17.20 \%$ and $\mathrm{Fs}=10.14 \%$ as compared to initial settings.

\section{References}

Angappan, P., Thangiah, S. and Subbarayan, S. (2017) 'Taguchi-based grey relational analysis for modeling and optimizing machining parameters through dry turning of Incoloy $800 \mathrm{H}^{\prime}$, Journal of Mechanical Science and Technology, Vol. 31, No. 9, pp.4159-4165.

Babu, D.M., Kiran, S.V., Vundavilli, P.R. and Mandal, A. (2016) 'Experimental investigations and multi-response optimisation of wire electric discharge machining of hypereutectic Al-Si alloys', International Journal of Manufacturing Research, Vol. 11, No. 3, pp.221-237.

Bouacha, K., Yallese, M.A., Mabrouki, T. and Rigal, J.F. (2010) 'Statistical analysis of surface roughness and cutting forces using response surface methodology in hard turning of AISI 52100 bearing steel with CBN tool', International Journal of Refractory Metals and Hard Materials, Vol. 28, No. 3, pp.349-361.

Brecher, C., Epple, A., Neus, S. and Fey, M. (2015) 'Optimal process parameters for parallel turning on shared cutting surfaces', International Journal of Machine tools and Manufacture, Vol. 95, pp.13-19. 
Budak, E. and Ozturk, E. (2011) 'Dynamics and stability of parallel turning operations', CIRP Annals, Vol. 60, No. 1, pp.383-386.

Chinchanikar, S. and Choudhury, S.K. (2013) 'Modelling and evaluation of flank wear progression of coated carbide tools in turning hardened steels', International Journal of Manufacturing Technology and Management, Vol. 27, No. 1(3), pp.4-17.

Deng, J.L. (1989) 'Introduction to grey system', Journal of Grey System, Vol. 1, No. 1, pp.1-24.

Dieguez, J.L., Ares, J.E. and Marcos, M. (2007) 'Multivariable analysis methods applied to variables optimisation in manufacturing processes', International Journal of Manufacturing Research, Vol. 2, No. 2, pp.171-178.

Gopikrishnan, A., Kanthababu, M., Mathew, N.T., Gowri, S. and Balasubramaniam, R. (2015) 'Multi-objective optimisation in the micro-turning of cobalt chromium with coated and uncoated tools using the grey relational analysis', International Journal of Precision Technology, Vol. 5, No. 1, pp.44-61.

Kalidasan, R., Ramanuj, V., Sharma, D.K. and Senthivalen, S. (2014) 'Influence of cutting speed and offset distance over cutting tool vibration in multi-tool cutting vibration', Advanced Material Research, Vols. 984-985, pp.100-105.

Kalidasan, R., Senthilvelan, S. and Dixit, U.S. (2017) 'An experimental study of surface roughness in double tool turning process', International Journal of Additive and Subtractive Materials Manufacturing, Vol. 1, No. 3(4), pp.310-327.

Kalidasan, R., Senthilvelan, S., Dixit, U.S. and Vaibhav, J. (2016) 'Double tool turning: machining accuracy, cutting tool wear and chip-morphology', International Journal of Precision Technology, Vol. 6, No. 2, pp.142-158.

Kumar, S., Yadav, R.N. and Kumar, R. (2017) 'Experimental studies on duplex turning of titanium alloy (Ti-6Al-4V)', IEEE International Conference on Advances in Mechanical Industrial Automation and Management System, Organized (AMIAMS 2017), MNNIT, Allahabad, Vol. 1, p.42.

Kumar, S., Yadav, R.N. and Kumar, R. (2019) 'Multi-response optimization of duplex turning of nickel alloy using grey relational analysis with entropy measurement', Engineering Research Express, Vol. 1, No. 2, p.025006.

Kumar, S., Yadav, R.N. and Kumar, R. (2020) 'Empirical modeling and multi-response optimization of duplex turning for Ni-718 alloy', International Journal of System Assurance and Engineering Management, Vol. 11, No. 1, pp.126-139.

Manivel, D. and Gandhinathan, R. (2016) 'Optimization of surface roughness and tool wear in hard turning of austempered ductile iron (grade-3) using Taguchi method', Measurement, Vol. 93, pp.108-116.

Meddour, I., Yallese, M.A., Bensouilah, H., Khellaf, A. and Elbah, M. (2018) 'Prediction of surface roughness and cutting forces using RSM, ANN, and NSGA-II in finish turning of AISI 4140 hardened steel with mixed ceramic tool', The International Journal of Advanced Manufacturing Technology, Vol. 97, No. 5(8), pp.1931-1949.

Mishra, K., Mukhopadhyay, P., Sarkar, B.R., Doloi, B. and Bhattacharyya, B. (2018) 'Improvement of micro-EDM performances with aid of vibration', International Journal of Precision Technology, Vol. 8, No. 1, pp.38-65.

Mohapatra, K.D., Dash, R. and Sahoo, S.K. (2017) 'Analysis of process parameters in wire electric discharge machining of gear cutting process using entropy grey relational analysis approach', International Journal of Manufacturing Research, Vol. 12, No. 4, pp.423-443.

Mukherjee, I. and Ray, P.K. (2006) 'A review of optimization techniques in metal cutting processes', Computers and Industrial Engineering, Vol. 50, No. 1(2), pp.15-34.

Palanisamy, A. and Selvaraj, T. (2018) 'Optimisation of turning parameters on heat treated Incoloy $800 \mathrm{H}$ using cryogenically treated CVD tool with grey-based entropy method', International Journal of Machining and Machinability of Materials, Vol. 20, No. 5, pp.401-424. 
Pawade, R.S. and Joshi, S.S. (2011) 'Multi-objective optimization of surface roughness and cutting forces in high-speed turning of Inconel 718 using Taguchi grey relational analysis (TGRA)', The International Journal of Advanced Manufacturing Technology, Vol. 56, No. 1(4), pp.47-62.

Pradhan, M.K. (2012) 'Determination of optimal parameters with multi response characteristics of EDM by response surface methodology, grey relational analysis and principal component analysis', International Journal of Manufacturing Technology and Management, Vol. 26, No. 1(4), pp.56-80.

Pradhan, M.K. (2018) 'Optimisation of EDM process for MRR, TWR and radial overcut of D2 steel: a hybrid RSM-GRA and entropy weight based TOPSIS approach', International Journal of Industrial and Systems Engineering, Vol. 29, No. 3, pp.273-302.

Priyadarshini, M. and Pal, K. (2016) 'Multi-objective optimisation of EDM process using hybrid Taguchi-based methodologies for Ti-6Al-4V alloy', International Journal of Manufacturing Research, Vol. 11, No. 2, pp.144-166.

Rao, R. and Yadava, V. (2009) 'Multi-objective optimization of Nd: YAG laser cutting of thin superalloy sheet using grey relational analysis with entropy measurement', Optics and Laser Technology, Vol. 41, No. 8, pp.922-930.

Rose, P.J. (1996) Taguchi Technique for Quality Engineering, Tata McGraw-Hill, New York.

Satyanarayana, K., Gopal, A.V. and Ravi, N. (2015) 'Studies on surface integrity and its optimisation in turning Ti-6Al-4V', International Journal of Precision Technology, Vol. 5, No. 3(4), pp.312-329.

Sharma, A. and Yadava, V. (2011) 'Optimization of cut quality characteristics during Nd: YAG laser straight cutting of Ni-based superalloy thin sheet using grey relational analysis with entropy measurement', Materials and Manufacturing Processes, Vol. 26, No. 12, pp.1522-1529.

Sivaiah, P. and Chakradhar, D. (2017) 'Multi-objective optimisation of cryogenic turning process using Taguchi-based grey relational analysis', International Journal of Machining and Machinability of Materials, Vol. 19, No. 4, pp.297-312.

Subburam, V., Ramesh, S., Kumar, P.M. and Srinivasan, A. (2018) 'Performance optimisation of electrochemical micromachining of micro-holes on Inconel 625 alloy', International Journal of Precision Technology, Vol. 8, No. 1, pp.66-84.

Suhail, A.H., Ismail, N., Wong, S.V. and Jalil, N.A. (2012) 'Surface roughness identification using the grey relational analysis with multiple performance characteristics in turning operations', Arabian Journal for Science and Engineering, Vol. 37, No. 4, pp.1111-1117.

Suneesh, E. and Sivapragash, M. (2019) 'Parameter optimisation to combine low energy consumption with high surface integrity in turning $\mathrm{Mg} / \mathrm{Al}_{2} \mathrm{O}_{3}$ hybrid composites under dry and MQL conditions', Journal of the Brazilian Society of Mechanical Sciences and Engineering, Vol. 41, No. 2, p.89.

Tang, L., Landers, R.G. and Balakrishnan, S.N. (2008) 'Parallel turning process parameter optimization based on a novel heuristic approach', Journal of Manufacturing Science and Engineering, Vol. 130, No. 3, p.031002.

Thakur, A., Manna, A. and Samir, S. (2019) 'Multi-response optimization of turning parameters during machining of EN-24 steel with SiC nanofluids based minimum quantity lubrication', Silicon, Vol. 12, No. 1,pp.1-15.

Tosun, N. (2006) 'Determination of optimal parameters for multi-performance characteristics in drilling by using grey relational analysis', International Journal of Machining and Machinability of Materials, Vol. 28, No. 5, pp.450-455.

Velayutham, K., Venkadeshwaran, K. and Selvakumar, G. (2018) 'Optimisation of laser cutting of SS 430 plate using advanced Taguchi entropy weighted-based GRA methodology', International Journal of Mechatronics and Manufacturing Systems, Vol. 11, No. 2(3), pp.148-166. 
Viswanathan, R., Ramesh, S. and Subburam, V. (2018) 'Measurement and optimization of performance characteristics in turning of $\mathrm{Mg}$ alloy under dry and MQL conditions', Measurement, Vol. 120, pp.107-113.

Wen, K.L., Chang, T.C. and You, M.L. (1998) 'The grey entropy and its application in weighting analysis', IEEE International Conference on in Systems, Man, and Cybernetics, Vol. 2, pp.1842-1844.

Yadav, R.N. (2017) 'Development and experimental investigation of duplex turning process', Advances in Manufacturing, Vol. 5, No. 2, pp.149-157.

Yadav, R.N. (2018) 'An experimental study and parameters optimization of duplex turning process', Materials Performance and Characterization, Vol. 7, No. 1, pp.423-444.

Yadav, U.S. and Yadava, V. (2015) 'Experimental modelling and optimisation of process parameters of hole drilling by electrical discharge machining of aerospace titanium alloy', International Journal of Manufacturing Technology and Management, Vol. 29, No. 3(4), pp.211-234.

Zerti, A., Yallese, M.A., Meddour, I., Belhadi, S., Haddad, A. and Mabrouki, T. (2019) 'Modeling and multi-objective optimization for minimizing surface roughness, cutting force, and power, and maximizing productivity for tempered stainless steel AISI 420 in turning operations', The International Journal of Advanced Manufacturing Technology, Vol. 102, No. 1(4), pp.135-157. 